\title{
Patients' experiences of being nursed by student nurses at a teaching hospital
}

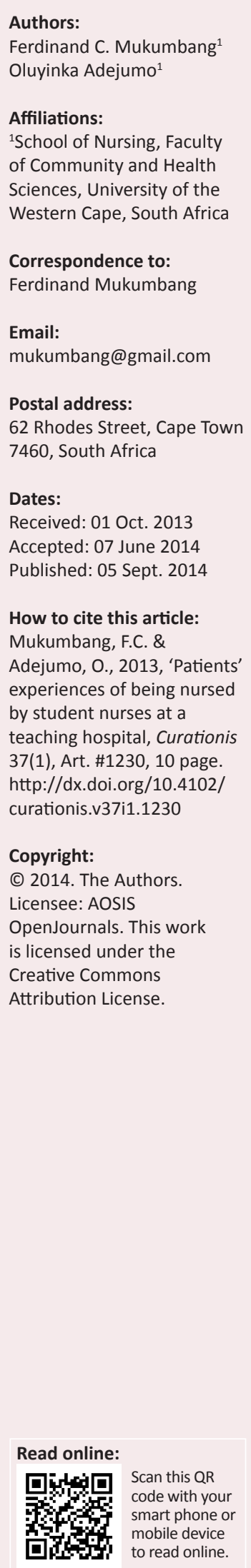

Background: Teaching hospitals are medical institutes at which most nursing education institutions provide their students with practical nursing experience. Although the focus of care is the patient, attention is sometimes focused more on the nursing students rather than on the patients who are undergoing care at the hands of both the nursing professionals and students. However, proper nursing care should also take into account the experiences of patients during the care process in the health facility.

Objectives: The study had three objectives: to describe the experiences of patients nursed by student nurses in a teaching hospital in the Western Cape; to identify patterns in the experiences of patients receiving patient care from student nurses; and to analyse aspects of the experiences that may need further attention for the training of student nurses.

Method: A descriptive phenomenological approach was used to explore the experiences of patients nursed by student nurses. Participant selection took place purposively from different wards of the identified teaching hospital, and thematic saturation was achieved at 10 participants. The data were collected through in-depth interviews and analysed using thematic content analysis.

Results: Three main themes were discovered after data analysis: methods of identification of student nurses by patients; positive perceptions of student nurses by patients; and negative perceptions of student nurses by patients.

Conclusion: The findings will inform the clinical supervisors and educational institutions of aspects of the nursing training of student nurses that need improvement and those that require enforcement.

\section{Introduction}

Patient-centred care in contemporary nursing refers to prioritising the patient and their experience through the process of 'communication, discussion of treatment options, potential outcomes and possible psychological effects' (Royal College of Nursing 2013). These are what is expected of a professional nurse practising in the 21st century. The mandate of nursing education institutions is to prepare and produce nurses capable of rendering nursing care that is appropriate for the health needs of society. In order to best prepare these student nurses, they are exposed to hospital-based training in teaching hospitals to achieve emotional stamina and comprehensiveness in training. This need for hospital-based exposure for nursing students in nursing education has driven nursing training institutions and other stakeholders to allocate teaching hospitals for clinical practice purposes.

Patients admitted to such health facilities are more often than not aware that these are teaching hospitals where student nurses undergo clinical training on live patients. For nursing students contact with patients constitutes a very important part of their nursing training, as this exposure naturally gives rise to the student-patient relationship (Kulkarni 2009:72). When these nursing students nurse patients, an inevitable student nurse-patient relationship is being formed, which is described as the essence of nursing care (Moley 2003:103). This care provider-patient relationship provides the foundation for the care experience (Koloroutis 2004:72). As a result, the student nurse-patient relationship is deemed to form the basis of the experiences of patients nursed by student nurses.

\section{Problem statement}

Factors such as students' and patients' mutual prejudices and attitudes have been found to influence the patient-student relationship (Suikkala \& Leino-Kilpi 2005). However, a plethora of recent studies conducted around this relationship mostly focus on the experiences of students (Skaalvik, Normann \& Henriksen 2010; Warne et al. 2010), their perceptions (Doucette et al. 2011), 
feelings (Parry 2011), and adaptations (Ironside, Diekelmann \& Hirschmann 2005) towards the patients, clinical placements and the nursing programme in general. There is a dearth of empirical studies that explore the experiences of patients upon whom the student nurses perform their nursing practices. This observation is confirmed by the Saskatchewan Ministry of Health (2009:3) that broadly states that 'there is very little research that examines healthcare integration from the patient perspective.'

\section{Aim of the study}

The purpose of this study is to explore the experiences of patients at a teaching hospital who were nursed by student nurses.

\section{Research objectives}

In order to successfully achieve the aim of the study, it is designed to meet the following research objectives:

- Describe the experiences of patients nursed by student nurses in a teaching hospital in the Western Cape.

- Identify patterns in the experiences of patients receiving patient care from student nurses.

- Analyse aspects of the experiences that may need further attention during the training of student nurses.

\section{Definition of key concepts}

Patient's experience: This refers to the feelings, thoughts and knowledge shared by patients that influence the way they react, think or behave. 'Patient experience is the sum of all interactions, shaped by an organization's culture, that influence patient perceptions across the continuum of health' (The Beryl Institute 2010).

Nurse: To look after someone who is ill or injured with the goal of making them feel well and fulfilled (MedicineNet. com 2014a).

Nursing student: Someone undergoing education and training to become a professional nurse or training in basic nursing (Department of Health 2008:5).

Patients: People admitted to hospital because they are not well or have ailments, injuries or are suffering from a medical condition that requires medical and nursing intervention (MedicineNet.com 2014b).

Teaching hospital: A hospital that provides clinical education and training to doctors, nurses and other health professionals, in addition to delivering medical care (Rani 2012:1).

Therapeutic encounter: Contact between at least two people which is designed to enhance the health of one or more of those engaged in the contact (Wayne 2005:1246).

\section{Contribution to field}

'Every relationship between a nurse and her patients - or between her and any other person in the school or hospital situation - involves a learning experience', Peplau (1951:722). According to Rycroft-Malone et al. (2003:85) the experiences and preferences of patients should be the main focus in the practice of evidence-based health care. The findings of this study will therefore contribute to enhancing patient care, especially amongst those nursed by nursing students during their clinical training. This could be done by identifying those aspects of nursing care that are poorly executed by student nurses and putting training programmes in place to address them.

Secondly, it would inform the clinical supervisors and nursing educators in general of the possible experiences of patients nursed by student nurses in the course of nursing student training and assessments, allowing them to plan for better training strategies and procedures. This in turn will contribute to students' progress towards individual-oriented nursing practice. Working from the patients' perspective provides educators with an important foundation from which to develop the skills and refine the personalities necessary for effective nursing care (Lauder et al. 2002:488).

Thirdly, according to Dierckx de Casterlé et al. (2011:233), responsibility comes when student nurses become connected to their patients. Taking up the responsibility to nurse patients requires that the student nurses become aware of what 'patient needs' mean to the patients themselves. The clearer the patients' understanding of the care process, the better the students can know what their responsibility entails. This study could therefore provide insight into the experiences of patients as they perceive nursing care offered by student nurses. Knowing how patients perceive the care that they offer could lead the student nurses to become more responsible.

\section{Literature review}

Considering that the study is aimed at exploring the experiences of patients when nursed by student nurses, it is worth exploring the aspects of nursing care offered by student nurses that might prompt these experiences. In a study conducted by Sharif and Masoumi (2005) in Iran, to assess student nurses' experiences during clinical practice, a focus group design was used to investigate the nursing students' views of the clinical practice through organised discussions. It was concluded from four identified themes that students were not satisfied with the clinical component of their education. The four themes identified included 'initial clinical anxiety', 'theory-practice gap', 'clinical supervision', and 'professional role'. Initial clinical experience was the most anxiety-producing part of student clinical experience; fear of making mistakes and being evaluated by clinical supervisors were also expressed by students as anxietyproducing situations in their initial clinical experience. Also, most of the students had the perception that their clinical supervisors had a more evaluative role than a teaching role, which made them more anxious and prone to making mistakes. This anxiety and errors by the student nurses affect their ability to perform. 
In support of the findings of Sharif and Masoumi (2005), by reviewing the literature to examine existing research on the nursing student-patient therapeutic encounter between 1984 and 1998, Suikkala and LeinoKilpi (2001:42-50) obtained some interesting information. After reviewing over 484 articles obtained from the phrases 'nurse-patient relations', 'nursing students' and 'studentpatient relationships' from MEDLINE and CINAHL CDROM databases, they discovered that 'although students do approach the beginning of their work in clinical setting with eagerness and the desire to learn and grow, they also commonly felt tension and anxiety, especially as regards new or challenging interpersonal relations' (Suikkala \& LeinoKilpi 2001:232).

Listening to lived experiences of student nurses and other healthcare providers can help us to understand what it means to provide care in a specific situation or under particular conditions (Dierckx de Casterlé et al. 2011:232-242), and therefore to predict variations in patient experiences during healthcare provision.

In another study carried out by Reid-Searl, Moxham and Happell (2010:225-232) to explore the effects of student nurses' anxiety in patient care during clinical practice, they studied the effects of clinical practice anxiety on medication administration. Using the grounded theory approach, indepth semi-structured interviews were conducted with undergraduate nursing students to explore their experiences of administering medication in a clinical setting. The investigators found that almost one-third of participants reported making an actual error in medication or having a near-miss. They concluded that medication errors by nursing students have potential to significantly impact on patient safety, quality of healthcare, and nursing students' perceptions of their professional competence.

Considering that professional nurses also nurse these patients, they get the chance to identify appropriate nursing care processes and procedures, which allows them to identify mistakes made by student nurses during their clinical placements.

Having identified some aspects of the student nursepatient therapeutic relationship that could prompt various experiences during practitioner-patient rapport, it is worthwhile looking into those aspects of care that are important to the care process as seen by the patients. One such investigation was conducted by Bradley, Frizelle and Johnson (2010:210-228) to evaluate literature on patient-perceived care from online databases. They unearthed that patients value a person-centred approach that reduces isolation, increases social support, encourages communication and provides activities. From this study it would seem fair to assume that patients have perceptions of which aspects of care would incite good or bad experiences of the caring process.

To further investigate this assumption, De Boer, Delnoij and Rademakers (2010:285-297) conducted a quantitative study with patients with malignant breast cancer, hip and/or knee surgery, cataract surgery, rheumatoid arthritis, and diabetes. The aim of the study was to identify patient priorities regarding elements of care for the sampled disease conditions. Data were collected and analysed using five consumer quality index survey disease-specific questionnaires. They concluded that patient priorities varied between patient groups, which just goes to show that there is no direct causal relationship between nursing care and the experiences of patients. This suggests that other factors play important roles in patient experiences in the nursing care process.

To ascertain the fact that patient experience is a result of more than good nursing care, and also the result of other intervening factors, Irurita (1999) used grounded theory methodology to discover factors perceived by patients to influence delivery of high-quality nursing care. The findings revealed that in terms of quality of the care delivered, patients perceived different levels of the care process. The level of quality of care was found to depend on certain contextual and intervening conditions pertaining to the broader environment, the organisation and personal factors of the nurse and patient. Factors outlined as either inhibiting or enhancing the quality of nursing care are environmental factors, organisational factors, type of hospital, coordination and communication, patient information, consistency of caregivers, nurse-patient relationship and sufficient time, nurses being there when needed, personality and/or attitude of nurse, caring (empathy and compassion), and finally the technical skills of the nurse. This study sets out to explore the experiences of patients when nursed by student nurses in the light of the above-identified factors.

\section{Research method and design Research design}

A descriptive phenomenological research design was employed to answer the research question of this research. The population which this research is attributed to includes all patients who are and have been admitted to a hospital and have experienced being nursed by a student nurse.

In accordance to Creswell (2007; 2013) sampling was conducted at site level (hospital), at the event or process level (wards), and at the participant level (patients). Using purposive sampling the investigator selected the research site (teaching hospital in the Western Cape) and individuals for the study because they could purposefully inform the understanding of the research problem and central phenomenon of the study (Creswell 2007; 2013).

Firstly, sample selection for this study was carried out in a Western Cape teaching hospital in collaboration with the working nursing staff and clinical supervisors who were familiar with the functioning of the hospital systems and various wards. Secondly, the wards where the nursing students are allowed to practice were identified, which included the medical, surgical, orthopaedic, urology, trauma, 
gynaecological, neurology, dermatology, cardiology, theatre and intensive care unit. However, for various reasons some of these wards were not considered during the sample selection process. The neurology wards were excluded because of the variations in the state of consciousness of the patients. The theatre was not included because most of the students are not allowed the chance to participate in the care process, and the dermatology ward was excluded since there is usually limited care being offered to patients admitted there. Even though the gynaecological ward was included, the maternity ward for postpartum patients was not considered. Of the 11 potential wards identified, 6 were purposefully sampled for inclusion in the study.

Thirdly, at the patient level the investigator selected participants on the basis of the inclusion criteria identified below. However, there were some technicalities that disqualified other patients, such as their mobility status, medical and nursing care schedules and, of course, their willingness to participate. For some level of homogeneity in the sample population, the investigator recruited participants from all six wards pertaining to the three identified departments that were purposefully selected, ensuring that both male and female wards were included. The investigator therefore aimed at having at least one patient from each ward until saturation was obtained.

\section{Inclusion criteria}

Although people who have been nursed by student nurses are identified as the population of the study, the investigator considered the following criteria to guide inclusion in this study. The patient must:

- be 18 years of age and above;

- be able to understand and express his or herself in English, due to potential loss of meaning through the translation process;

- be admitted in the identified teaching hospital in the Western Cape;

- have been admitted for two days or more; and

- have experienced being nursed by a student nurse.

The investigator recruited participants from the target population until the study reached saturation.

\section{Data collection}

The data were collected through in-depth interviews with the research participants. Audiotapes were used to record the interviews, and descriptive questions were used to obtain information from the participants. These questions aimed to provide an extensive response based on the interviewee's expert knowledge of a particular subject, area or experience.
A standardised open-ended question that was structured in terms of wording was used during the interview: Could you please describe your experience when the student nurse was performing the injection administration on you (depending on the nursing care)? This gave respondents the chance to explain how they experienced the care being provided to them by student nurses, in exactly the way they perceived it. The investigator used probing questions such as: So what happened? What were your thoughts then? How did that make you feel? What did you decide then?, to prompt the participants for further explanations.

\section{Data analysis}

The data were analysed using thematic content analysis, through which it was possible to distill words into fewer content-related categories, with the assumption that when classified into the same categories these words and phrases shared a similar meaning.

\section{Context of the study}

This article is based on a mini-thesis submitted for completion of a Master's degree in Nursing Education from the University of the Western Cape.

\section{Results}

Three main categories were identified with corresponding themes, as outlined in Table 1.

\section{Theme one: Identification of student nurses by patients}

Considering that there are many different kinds of healthcare professionals who flood the wards of teaching hospitals, coupled with the fact that one of the inclusion criteria for the study was that the client must have been nursed by a student nurse, it was important to seek the means by which the patients recognised a student nurse. Four subthemes stood out in this main theme: self-introduction; identification of students through their dress code; identification through work competence; and inability to identify student nurses.

\section{Subtheme one: Self-introduction}

Self-introduction is the traditional way of introducing oneself before a health provider proceeds to perform any healthcare services. Similarly, students are taught to introduce themselves to the patients as well as to state their status as a student nurse before they carry on with any nursing care acts that they have planned for the patients. During the interview process some patients attested to recognising student nurses through self-introduction. Participant 2 explained that: 'They [nursing student] come and introduce themselves before

TABLE 1: Main categories and themes that emerged from the data.

\begin{tabular}{lll}
\hline Identification of student nurses by patients & Positive perceptions of student nurses & Negative perceptions of student nurses \\
\hline $\begin{array}{l}\text { Self-introduction. } \\
\text { Identification of students through their dress code. }\end{array}$ & $\begin{array}{l}\text { Patients feel comfortable with student nurses and } \\
\text { acknowledge their work. }\end{array}$ & $\begin{array}{l}\text { Lack of competency in some nursing procedures. } \\
\text { Identification through work competence. }\end{array}$ \\
$\begin{array}{ll}\text { Supportive and willing to be of service to patients. } \\
\text { Inability to identify student nurses. }\end{array}$ & Students are skilful and competent in their nursing roles. & Negative feelings leading to lack of trust in the student nurses. \\
\hline
\end{tabular}


they examine you and before they talk to you.' Participant 3 expressed that should the student nurse or the care provider fail to introduce themselves, he would ask them for a selfintroduction: 'I ask, especially the new ones; the new faces. I ask them if they are new and what year.' These responses from some of the study respondents showed that self-introduction by students prior to performing a nursing procedure is one of the ways in which patients identify student nurses during nursing practice.

\section{Subtheme two: Identification of students through their dress code}

The data obtained indicate that some of the patients in the teaching hospital recognise the nursing students by way of their dressing. The Minister of Health, in terms of section 11(1) of the Nursing Act, Act 69 of 1957, approved a dress code for student nurses during their practice in hospital. According to this act, revised in 2011, student nurses must wear a plain white top and a pair of navy blue pants or skirt.

The identification is captured in statements such as this one by participant 8 : 'They all wear pants but they have a plain white top'. Whilst the patients identify the student nurses through their dress code, the data revealed that the dress code is also used as a means of differentiating the student nurses from the qualified nurses employed by the institution. The patients recognise that qualified nurses have epaulettes that spell out their different grades and qualification, as expressed by participant 4 :

'... by their uniform. Some of them have got the blue and the maroon on their shoulders, that is how you will look out who is the nurse and who is the student.'

Part of the dress code of the students stipulates that they should wear their identification badges at all times whilst on duty. These identification badges also serve as a means by which some of the patients identify the student nurses, as stated by participant 1: 'Then some people come here like the nurses, then you can read here [pointing at the breast pocket].' Through the uniforms, epaulettes and name tags patients could positively identify students as they carried out nursing duties in the hospitals.

\section{Subtheme three: Identification by services}

Although some patients identify student nurses through their dress code, others identify and judge the care provider based on the competence of the care provider. According to some of the study participants it is only when the student nurses have performed the intended procedure that they are able to judge whether it is a student or a qualified nurse who performed the procedure. For instance, participant 5 stated that 'They [student nurses] don't have so much experience like the professional nurse.' Meanwhile others identify them by the types of services that they offer to the patients. This is construed from a statement made by participant 6: 'You can see on the works that they do, if you look at the work that they do.'
According to the South African Nursing Council nursing students are only allowed to perform certain acts pertaining to nursing. Moreover, they can only carry out these procedures if they: (1) have been taught by nursing educators or clinical supervisors at their nursing institutions; (2) have the knowledge, skill and judgement to perform them as determined by their clinical supervisors or head nurse; or (3) are supervised by a member of the nursing staff or the clinical supervisors. As a result of these precautionary measures, patients could actually distinguish those acts performed by nursing students and also judge their competency levels through the ways in which these nursing care acts were performed.

\section{Subtheme four: Inability to identify student nurses}

Although there are many measures that have been put in place to ensure that patients recognise student nurse care providers (dress code, identification badges, self-introduction, etc.) before they perform any nursing services on them, there is evidence from the data collected that three patients failed to identify student nurses who provided nursing care to them. During the interview process a patient indicated that it was only after the procedure had been performed that she became aware that it was a student who had provided the care services. This was as a result of the bad experiences she had during the procedure. In her own words, participant 7 said: 'they said it was a student'. From this patient's comments one can see that she failed to identify the care provider as a student prior to the procedure being performed.

\section{Theme two: Positive perceptions of student nurses}

Many of the patients who took part in the study had positive experiences with the student nurses, especially with the physical aspects of nursing care they offered. They expressed positive aspects of having nursing students tend to their healthcare needs; they said the students were 'helpful', 'did a very good job', were 'quite excellent', 'caring', 'friendly', 'very good' and 'wonderful'. These feelings and perceptions were classified under the following subthemes: patients feel comfortable with student nurses and acknowledge their work; supportive and willingness to be of service to patients; and students are skilful and competent in their nursing roles.

\section{Subtheme one: Patients feel comfortable with student nurses and acknowledge their work}

The data collected suggest that patients feel comfortable with the students when they provide nursing care to them. The data also indicate that, not only do these patients feel comfortable, they also acknowledge that the students are doing a good job. Six participants were very expressive about how comfortable they felt with the student nurses: For example, participant 3 reported:

'To tell the truth, most of the time I feel very comfortable with the procedure and they also help you when you don't understand 
something, like when they understand something about my body.'

A similar finding was reported by Andresen and McDermott (1992:23), when they noted that patients tend to be satisfied with students' interpersonal skills and especially with their skills in teaching and listening. Mossop and Wilkinson (2006:52) also made the same finding when they explored perceptions of elderly clients of student nurses. They observed that the elderly clients appreciated the efforts of the students to increase their level of comfort during their practicum. Feeling comfortable with students makes the patients appreciate the work that the student nurses do. This was overtly expressed by a respondent as he said 'I do appreciate the work of students. I appreciate it.' A study conducted by Debyser et al. (2011:201), in which they explored the extent to which a client's feedback on the student's work performance is consistent with feedback from the mentor, revealed that patients do appreciate students and the work that they do, especially students who are authentic, spontaneous and sensitive.

\section{Subtheme two: Supportive, helpful and willing to be of service}

One of the most outstanding experiences of the patients nursed by student nurses was the supportive and helpful attitude of the student nurses, expressed in their willingness to be of service to the patients. Eight of the 10 respondents expressed this experience in very positive words. Participant 1 said:

'She [student nurse] was very good to me and she asked me if I wanted some water, or wanted to pee, what can she do to me? I don't see anything wrong in the student nurse.'

\section{Participant 6 also shared that:}

'They're wonderful. They can be busy and you can call on them at any time, they'll leave whatever they're doing and they'll come and hear what you want and they see that they help you any way they can. I think they are excellent.'

This respondent gave evidence of the willingness of the student nurses to help the patients they are caring for.

As another respondent, participant 10, explained:

'When I ask them do me a favour, open the curtains, close the curtains for me, or they help me go to the toilet ... they help me; they put on my socks, when I don't have my socks on. If I call them they come, and ask them they must help me to the toilet, they don't waste time, they do it for me ... If I call them from here 'come help $\mathrm{me}^{\prime}$ then they come and help me. Sometimes I ask them if you got time please come cut my hair here [touching the hair on her chin], and so when they are free there they come and help me and cut my hair.'

This respondent demonstrated how far the student nurses are willing to go to make their patients comfortable, indicating their supportive role during nursing care.

One of the patients considered the student nurses to be so helpful that they are replacing qualified nurses who should have been employed. She (participant 4) pointed out that 'They're very helpful; they help the nurses do a lot because they are short-staffed. So they need their input, that is why.' This indicates that the patients find their role important, as the student nurses are making a contribution towards the smooth running of the wards. They have filled in the gap left by the lack of professional nurses being employed to carry out the nursing duties that need to be carried out.

In a study conducted by Mehta and Singh (2005:49) to assess perceptions of patients of student nurses, $84.86 \%$ of the clients said that the student nurses provide much help in the treatment process. This result aligns with the study findings on the helpful nature of student nurses as experienced by the respondents.

To elaborate of their supportive role, participant 6 clarified as follows:

'They're [student nurses] very friendly. Some of them can come and sit and have conversation with you also. When they're not busy, they will come and talk to you. Then you don't feel so lonely also. Some of us don't often get visitors, so they come and talk to you, cracking jokes sometimes ... They will come and sometimes brighten up your day by cracking a joke.'

\section{Participant 8 elucidated that:}

'They [student nurses] come in, if you can't wash, they will help you wash; that is all positive, okay. They will ask you if there is anything you need, tidy your bed, they will chat to you. Some of them is quiet, some of them will chat to you. If you're quiet, they will ask you how are you today, good morning, and so on ... and if you're not in the conversation, they will just stay back. But if you keep on talking, they keep on talking, and that's nice.'

In support of the evidence presented above, Suikkala and Leino-Kilpi (2001:46) found that patients enjoyed the company of students and found their visits helpful. Debyser et al. (2011:201) discovered that most patients felt that students were spending enough time with them, and enjoyed their company. They also thought some students were sensitive to the client as a person by spending more time with them. In a study conducted by Mossop and Wilkinson (2006:51) to explore what elderly patients think of student-rendered care, the clients expressed that students enhanced their social life, providing them with opportunities to interact socially. Some of the clients mentioned that they enjoyed the company of the nursing students and found that their presence 'relieved loneliness and depression' (Mossop \& Wilkinson 2006:51).

\section{Subtheme three: Students are skilful and competent in their nursing roles}

One of the positive subthemes that emanated from the data analysis related to the skills and competence of the student nurses in carrying out their nursing roles. Three of the research participants commented on the quality skills displayed and the high competency level of the student nurses in performing their nursing roles. One respondent expressed his experience in these words: 
'The first injection by a student, I told the student you know your work because I didn't feel nothing. She didn't inject me here [pointing to the stomach muscles]. I didn't feel nothing at all. Another two students came and gave me two injections in the stomach; she did it so nicely, man, not in a rough way. I didn't feel anything ... but the student she did a very good job, man. I told her you know your job. She said thank you. Honestly, she said thank you. Because she put the needle nicely in and she took it nicely out.' (Participant 2)

This detailed description by this respondent supports the fact that they feel positive about the nursing skills and competence of the student nurses. Whilst the first respondent talked about an invasive procedure, a second respondent described her experience with a student nurse whilst she performed physical nursing duties:

'They greet you smiling and they'll call you by your name. ... "I've come to take your blood pressure, if it's okay? I've come to take your pulse and temperature." And if it is not right, they will ask you if you are warm enough, "Are you comfortable, because your temperature is not right?". Then they do it again to see if it's not something wrong with the thermometer, and then it comes right [giggles].' (Participant 8)

These two descriptions from respondents indicate their positive experiences with respect to the skills displayed and competencies of the student nurses. In support of these findings, the study conducted by Mossop and Wilkinson (2006:52) also showed that most of the respondents believed students were as competent as the other qualified nurses, and used words such as 'efficient', 'thorough', 'very good' and 'they knew what to do.'

\section{Theme three: Negative perceptions of student nurses}

Whilst most of the respondents had positive perceptions of the student nurses performing nursing care on them, four participants had some negative experiences of their encounters with the student nurses in their therapeutic relationship. These findings concur with the conclusions drawn by Debyser et al. (2011:201), stipulating that although some clients described positive experiences with students' nursing care, others described negative experiences of their interaction with student nurses.

In this study respondents used words such as 'it was not nice', 'there are student nurses who are rude', 'that person can't do injection', and 'it really hurt' to describe their experiences with some student nurses. These negative experiences have been further divided into three subthemes identified from the data-coding process: lack of competency in some nursing procedures; display of poor professional behaviour and interpersonal skills; and negative feelings leading to lack of trust in the student nurses.

\section{Subtheme one: Lack of competency in some nursing procedures}

Four respondents expressed that during their therapeutic encounter with student nurses they experienced that the student nurses were incompetent or did not perform the required procedure as well as other student nurses or the professional nurses. In one such interview participant 5 said:

'Oh no, I had [received a drip administration] but it was not nice ... he [student nurse] put in the needle, he was shivering and it hurt me. So I said to him to go and call the doctor because I was quite sore when he put the drip on and he can't put the needle in properly.'

Participant 7, who experienced a similar situation, reported that:

'Monday you go, they must take blood first and she [student nurse] had to take my blood ... That person can't do injection ... I thought I was going to die ... because it really hurt.'

Participant 3 simply said that 'they don't know how to look for the veins and they don't know how to put the needle [in].'

These respondents describe experiences with student nurses who did not carry out their nursing procedures competently, which indicates that patients do encounter unpleasant experiences with student nurses. These findings were similar to a theme discovered when Mossop and Wilkinson (2006:52) explored the experiences of elderly patients when cared for by student nurses. They uncovered that some patients did not consider the student nurses as knowledgeable and competent enough to provide nursing care to patients.

\section{Subtheme two: Display of poor professional behaviour and interpersonal skills}

The data analysis also unearthed the fact that patients experienced some displays of poor professional behaviour and attitude from the student nurses. Poor professional behaviour is related to the way in which the student nurses sometimes responded to the needs of the patients. Their professional attitude relates to the way they spoke and related to patients during their caring sessions. According to some of the respondents, the students sometimes displayed poor professional behaviour and practice. Participant 4 explained as follows:

'Today she was busy emptying my bags [urine collector and stoma], and she emptied the one bag and the sister sent her to the chemist. And then she left without telling the sister that she is busy with a patient. And then when she came back she continued with whatever thing that she did.'

This respondent recounts a situation where the student nurse interrupted the care of a client to answer a lesser important call that was made by the sister in command. When the student nurse returned from the errand, she completely abandoned the client without completing her caring process, which made the client unhappy. The respondent explained:

'... I had to call her back to tell her she emptied the one bag, what about the stoma, which was swollen as well. And then for the second round when they came again around to come do the things, she emptied the stoma but she didn't empty the rest of my bags.' (Participant 4) 
This respondent described a classic example of unprofessional behaviour. To elucidate this point further, another respondent (participant 3) explained that whilst the students gathered around her bed to perform the vital signs check, they were hardly focused on the task at hand:

'They are busy talking about their stuff. That thing and that thing, and I'm also busy asking the questions ... I just lay down like this and think when are these people going to finish, or why did I say yes [laughs]. I do that. Sometimes I am quite comfortable with the procedure.' (Participant 3)

With respect to professional attitudes, four of the participants (25\%) reported incidents of poor professional attitudes displayed by the student nurses. Participant 10 recollected her experiences with some student nurses as follows:

'... sometimes in the night, there are student nurses who are rude. I must tell you that. If I tell them "Come help me", "No you, your legs is not off", and I can't walk this machine to the toilet [pointing at her dialysis machine]. Then I simply ask them to simply help me to the toilet with the machine, and then they say "No, you must help yourself".

This report outlines an experience of poor professional attitude displayed by student nurses working on the night shifts in the hospital wards. To corroborate these findings, in a study designed to obtain the perceptions of patients of nursing students in a hospital, $25.4 \%$ of the patients indicated that the students behaved badly to patients during their clinical practice (Mehta \& Singh 2005:49). From the above evidence it can be observed that negative behaviour towards patients form part of the experiences of the patients when being nursed by student nurses.

\section{Subtheme three: Negative feelings leading to lack of trust in the student nurses}

This theme portrays the negative feelings that patients experienced whilst they underwent nursing care provided by student nurses. The following comments describe how some of the respondents felt when they were nursed by student nurses: 'I felt kind of bad because I am also a patient at the end of the day' (participant 4); another (participant 5) said after injection administration by a student nurse '... he put in the needle, he was shivering and it hurt me.' Participant 7 expressed that she thought she was going to die due to the pain she experienced when a student nurse tried to collect a blood sample from her for her cancer screening tests: 'I thought I was going to die ... because it really hurt.' An incident recounted by participant 3, that occurred whilst another student nurse collected blood samples from the patient, suggested a similar experience.

The instances cited by the respondents portray experiences that were not positive or desirable. It was observed that these feelings followed either a poorly executed nursing procedure or a poor display of professional behaviour and interpersonal skills by the student nurses. As a result of the negative experiences that some of the patients had during their encounters with student nurses, some of them developed mistrust in the nursing care offered by student nurses, especially when it involved invasive nursing procedures. Participant 7 explained: 'Even here when I have to get injection I always make sure it is somebody who knows what they are doing, because I've got a fear of needle ...'

Another respondent felt sceptical in their abilities, and judged their competence by the manner in which they approached her:

'Sometimes my reaction is "I don't feel like it. I'm feeling tired", but sometimes when you approach me nicely with a smile or something, then I say OK fine. It's your attitude, it's your approach that you come to me that I say yes or no.' (Participant 3)

She was very clear on her position that it is the way in which the student nurse approaches her that makes her allow them to carry out invasive nursing care procedures or not. This finding is concurred with Morgan and Sanggaran (1997:423), who observed that although patients could develop trusting relationships with student nurses, they sometimes felt insecure in such relationships.

\section{Ethical considerations}

To ensure that the research addressed ethical issues, the proposed study was submitted to the Ethics Committee of the Senate of the University of the Western Cape, the Ethical Committee of the Department of Health of the University of Cape Town, and the Nursing Management Committee of the hospital where the research took place. Before a participant was recruited for this study, an information sheet describing the study and the role of the participant and a consent form was sent to the potential participant either by fax, email or post. Interviewing of participants took place only after they had signed the consent forms. To ensure that confidentiality of the participants' information is maintained, all of the recordings and transcriptions are locked in a safe drawer during the studies and for three years thereafter. The tapes as well as transcriptions will be burnt after a period of three years. Confidentiality was achieved by replacing the actual names of the research participants with code names and numbers, and only the investigator could match them.

\section{Trustworthiness}

After transcribing the different interviews the investigator returned to the interview participants to cross-check that the information provided was exactly what was transcribed, and whether that was what they intended to say. For this to be possible the transcriptions of interviews were done immediately after the interview process, so that the patients could be met the next day for participant checking. They were given the opportunity to add or remove any information that they wanted to. When the data analysis was completed, the interviews were sent to an independent coder at the University of the Western Cape and another private independent coder for a second opinion. Using the Delphi technique the two independent coders and the investigator 
all agreed that the themes obtained are a reflection of the data collected.

\section{Discussion}

The findings of this study provide insight into the experiences of patients when they are being nursed by student nurses in teaching hospitals. They showed that the experiences of the patients varied considerably. Some patients thought that the nursing students were as good as the qualified professional nurses working in the wards, whereas others thought the students had little to offer and should stick to the physical care part of the nursing process, and leave the invasive procedures to the professionals. With respect to the second objective of the study, to identify patterns in the experiences of patients involved in patient care with student nurses, two patterns were identified: positive perceptions of student nurses, and negative perceptions of student nurses.

Under the positive perceptions of the student nurses, it was revealed that patients feel comfortable with student nurses and acknowledge that they perform commendable nursing services. Other positive experiences the patients had was that the student nurses are very supportive of their patients and are willing to be of service whenever the patients require them to be. The patients also experienced that some of the students were skilful and competent in their nursing roles.

With respect to negative experiences encountered by patients during a therapeutic encounter with student nurses in a teaching hospital, it was found that some of the students who nursed the patients were not very competent in the nursing procedures they performed. As a result of their incompetence, the patients are hurt, disappointed and apprehensive. A second finding that stood out in this category, as revealed by the patients, was that some patients experienced the displaying of poor professional behaviour and interpersonal skills by the student nurses. Finally, due to the experience of incompetent display of nursing skills and poor professional behaviour by some students, some patients developed a lack of trust in the student nurses and were apprehensive about the nursing students.

\section{Limitations of the study}

In the strictest empirical sense of generalisability, the results obtained from qualitative studies such as this only apply to the participants interviewed. However, according to Hycner (1985:295), in the process of investigating even the experience of one unique individual, we can learn much about the phenomenology of human beings in general.

\section{Recommendations}

The third objective related to this study was to analyse aspects of the experiences that may need further attention for the training of student nurses. This analysis stems from the results obtained from the data analysis and interpretation processes. This objective aligns with the recommendations of the study, and is thus discussed as such.
From the first category relating to the identification of student nurses by patients, one of the themes identified was the lack of student identification by patients. One participant expressed concerns about only learning the identity of a student nurse after a very bad experience in the therapeutic process. Although identification could be made through the student nurses' dress and name-tag, the recommended and professional means of identification is through self-introduction. A recommendation on student nurse identification is that more emphasis should be placed on proper self-introduction by the student nurses before any nursing procedure is performed on a patient. Role-plays could be prepared by nursing educators to help develop this skill in the student nurses.

The findings of the study show that patients being nursed by student nurses sometimes have unpleasant and negative experiences from the therapeutic encounter with student nurses, sometimes from poorly executed nursing procedures. Special precautions should be taken to ensure that the studentpatient relationship is planned to promote both patient and student safety, especially with regard to performance of invasive nursing procedures. Such precautions might include student nurse-clinical supervisor briefings during the clinical placements of students, which should be done prior to the student nurses carrying out nursing care on the patients. These briefings should cover aspects such as difficulties faced by the students whilst working with patients, knowledge gaps in the use of the various instruments, and application of various nursing techniques.

Patients in teaching hospitals are a diverse group, with conditions ranging from small ailments to more complex needs. It is essential that clinical supervisors in the various wards of the teaching hospital setting be educationally prepared, experienced clinical instructors who can monitor the clinical environment and take into account student skill levels and patient acuity to ensure safety of patients and students.

The findings of the study revealed that some students did not display appropriate interpersonal skills when communicating with the patients, thus leading to patients reporting instances of unpleasant experiences with the student nurses in this regard. Communication skills should be emphasised to the nursing students during their nursing training, particularly interpersonal skills.

Instances of poorly executed nursing acts or intervention procedures were reported by the patients as the origin of their bad experiences with the student nurses. These instances were mostly related to invasive nursing procedures. It is therefore important to identify care issues that would benefit from performance improvement. To achieve this, nursing educators and clinical supervisors should ensure that emphasis is placed on the mastery of invasive procedures such as injection administration; blood sample collection; and setting up intravenous lines. Not only should these 
procedures be mastered in theory, but they should be well practised on dummies for competency before being attempted on patients in the hospital during clinical placements.

\section{Conclusion}

The experiences of patients reveal the patients' perceptions vary across the continuum of health as they interact with the various healthcare providers and the organisation's culture. Therefore every aspect of their interactions should be carefully evaluated with the aim of better service provision. In teaching hospitals one of the groups of people who interact constantly with patients is student nurses. Investigating the experiences of patients as they undergo nursing care given by student nurses contributes to evaluation of the total experience of patients in a health institution. Consequently, addressing the negative issues and encouraging the positive aspects of the nursing care offered by nursing students would go a long way to improving the overall experiences of patients admitted to teaching hospitals.

\section{Acknowledgements}

We acknowledge the Centre of Teaching and Learning Scholarship (CENTALS) for project sponsorship. We also acknowledge the Ethical Committee of the University of the Western Cape and Faculty of Health Sciences Human Research Committee of the University of Cape Town for their valuable input in designing the studies to meet ethical standards. We also acknowledge the contributions of Dr Susan Terblanche, Mrs Jordana Smith and Mr Oswell Khondowe to completion of this work.

\section{Competing interests}

No conflict of interest has been declared by the authors.

\section{Authors' contributions}

F.C.M. (University of the Western Cape) was project leader. F.C.M. obtained ethical clearance for the project, performed the literature review, interview data collection and data analysis, and was responsible for final development of the manuscript. O.A. (University of the Western Cape) provided valuable guidance through the entire development of the article, and performed critical reviews on the manuscript and redirected acuity and finishing of the article. F.C.M. carried out the final corrections and organisation of the article according to the specifications of Curationis.

\section{References}

Andresen P.A. \& McDermott M.A., 1992, 'Client satisfaction with student care in a nurse-managed center', Nurse Education 17(3), 21-23. http://dx.doi. in a nurse-managed center, Nurse $\mathrm{Ed}$

Bradley, S.E., Frizelle, D. \& Johnson, M., 2010, 'Patients' Psychosocial Experiences of Attending Specialist Palliative Day Care: A systematic review,' Palliative Medicine 25(3), 210-228. http://dx.doi.org/10.1177/0269216310389222

Creswell, J.W., 2007, Qualitative Inquiry and Research design: Choosing among Five Approaches, Sage Publications, Los Angeles.

Creswell, J.W., 2013, Qualitative Inquiry and Research Design: Choosing Among Five Approaches, 3rd edn., Sage Publications, Los Angeles.

De Boer, D., Delnoij, D. \& Rademakers, J., 2010, 'Do patient experiences on priority aspects of health care predict their global rating of quality of care? A study in five patient groups,' Health Expectations 12(3), 285-297.
Debyser, B.M., Grypdonck, H.F., Defloor, T. \& Verhaeghe, S.T.L., 2011, 'Involvement of inpatient mental health clients in the practical training and assessment of mental health nursing students: Can it benefit clients and students?', Nurse Education Today 31, 198-203. http://dx.doi.org/10.1016/j.nedt.2010.06.001

Department of Health, 2008, Nursing Strategy for South Africa 2008, viewed 26 September 2013, from www.sanc.co.za/pdf/nursing-strategy.pdf

Dierckx de Casterlé, B., Verhaeghe, T.L.S., Kars, C.M., Coolbrandt, A., Stevens, M. Stubbe, M., Deweirdt, N., Vincke, J. \& Grypdonck, M., 2011, 'Researching lived experience in health care: Significance for care ethic', Nursing Ethics 18(2), 232242. http://dx.doi.org/10.1177/0969733010389253

Doucette, E., Brandys, D., Canapi K.P., Davis, A., DiNardo, J. \& Imamedjian I., 2011, 'The Intensive Care Unit as an untapped learning resource: A student perspective,' Dynamics 22(1), 19-23.

Hycner, R.H., 1985, 'Some guidelines for the phenomenological analysis of interview data', Human Studies 8, 279-303. http://dx.doi.org/10.1007/BF00142995

Ironside, P., Diekelmann, N. \& Hirschmann, M., 2005, 'Students' voices: Listening to their experiences in practice education', Journal of Nursing Education 44(2), 49-52.

Irurita, V.F., 1999, 'Factors affecting the quality of nursing care: The patient's perspective,' International Journal of Nursing Practice 5, 86-94. http://dx.doi. org/10.1046/j.1440-172x.1999.00156.x

Koloroutis, M. (ed.), 2004, Relationship-Based Care: A Model for Transforming Practice, Creative Health Care Management, Minneapolis, MN.

Kulkarni, V.G., 2009, 'The student-patient relationship: A student's perspective on the grey areas,' Journal of Postgraduate Medicine 55(1), 72.

Lauder, W., Reynolds, W., Smith, A. \& Sharkey, S., 2002, 'A comparison of therapeutic commitment, role support, role competency and empathy in three cohorts of nursing students', Journal of Psychiatric and Mental Health Nursing (9), 483-491. http://dx.doi.org/10.1046/j.1365-2850.2002.00510.x

MedicineNet.com, 2014a, Definition of Nurse, viewed 17 February 2014, from http:// www.medterms.com/script/main/art.asp?articlekey $=39154$

MedicineNet.com, 2014b, Definition of Patient, viewed 17 February 2014, from http://www.medterms.com/script/main/art.asp?articlekey=39154

Mehta, R.S. \& Singh, B., 2005, 'Patients' attitude towards nursing students of BPKIHS', Journal of Nepal Health Research Council 4(2), 45-50.

Moley, W., 2003, 'Nurse-patient relationship: A dichotomy of expectations,' International Journal of Mental Health Nursing 12, 103-109. http://dx.doi. org/10.1046/j.1440-0979.2003.00276.x

Morgan, S. \& Sanggaran, R., 1997, 'Client-centred approach to student nurse education in mental health practicum: An inquiry,' Journal of Psychiatric and Mental Health Nursing 4, 423-434. http://dx.doi.org/10.1046/j.1365-2850.1997.00091.x

Mossop, M. \& Wilkinson, T., 2006, 'What do elderly patients think of student-rendered care?', Journal of Gerontological Nursing 32(6), 49-55.

Parry, M., 2011, 'Student nurses' experience of their first death in clinical practice,' International Journal of Palliative Nursing 17(9), 448-453. http://dx.doi. org/10.12968/ijpn.2011.17.9.448

Peplau, H.E., 1951, 'Towards new concepts in nursing and nursing education,'American Journal of Nursing 51(12), 722-724.

Rani, M.F.A., 2012, 'Malaysia needs more teaching hospitals,' International Medical Journal Malaysia 11(2), 1-2.

Reid-Searl, K., Moxham, L. \& Happell, B., 2010, 'Enhancing patient safety: The importance of direct supervision for avoiding medication errors and near misses by undergraduate nursing students,' International Journal of Nursing Practice 16(3), 225-232. http://dx.doi.org/10.1111/j.1440-172X.2010.01820.x

Rosenberg, S., 2009, 'Therapeutic communication in the clinical setting.' Natural and Applied Sciences, 72-79, viewed 15 August 2014, from http://ctl.laguardia.edu/ journal/v3/pdf/Rosenberg.pdf

Royal College of Nursing, 2013, Patient-centred care, viewed 26 September 2013, from http://rcnpublishing.com/page/ns/students/clinical-placements/patientcentredcare

Rycroft-Malone, J., Seers, K., Titchen, A., Harvey, G., Kitson, A. \& McCormack, B., 2003, 'Nursing and Health Care Management Policy: What counts as evidence in evidence-based practice?', Journal of Advanced Practice 47(1), 81-90.

Saskatchewan Ministry of Health, 2009, Patient-Centered Care: An introduction to what it is and how to achieve it, Steven Lewis, Saskatoon, SK.

Sharif, F. \& Masoumi, S., 2005, 'A qualitative study of nursing student experiences of clinical practice,' BioMed Central Nursing 4, 6 .

Skaalvik, M.W., Normann, K.H. \& Henriksen, N., 2010, 'Student experiences of learning person-centered care of patients with Alzheimer's disease as perceived by nursing students and supervising nurses', Journal of Clinical Nursing 19, 2639-2648. http://dx.doi.org/10.1111/j.1365-2702.2010.03190.x

Suikkala, A. \& Leino-Kilpi, H., 2001, 'Nursing student-patient relationship: A review of the literature from 1984 to $1998^{\prime}$, Journal of Advanced Nursing 33(1), 42-50. http://dx.doi.org/10.1046/j.1365-2648.2001.01636.x

Suikkala, A. \& Leino-Kilpi, H., 2005, 'Nursing Student-Patient relationship: Experiences of students and patients', Nurse Education Today 25, 344-354. http://dx.doi. org/10.1016/j.nedt.2005.03.001

The Beryl Institute, 2010, Defining Patient Experience, viewed 30 December 2011 from http://www.theberylinstitute.org/?page=DefiningPatientExp

Warne, T., Johansson, U., Papastavrou, E., Tichelaar, E., Tomietto, M., Van den Bossche, A., \& Saarikoski, M., 2010, 'An exploration of the clinical experience of nursing students in nine European countries,' Nurse Education Today 30, 809-815. http:// dx.doi.org/10.1016/j.nedt.2010.03.003

Wayne, J.B., 2005, Mosby's Dictionary of Complementary \& Alternative Medicine, Elsevier Mosby, St Louis, Mo. 